\title{
CLINICAL EVALUATION OF FLUOTHANE WITH SPECIIAL REFERENCE TO A CONTROLLED PERCENTAGE VAPORIZER
}

\author{
IAIN M. MACKAY, M D., F.A.C.A.
}

EACH NEW DRUG which comes to the attention of the clinical investigator is destined to become the subject of controversy The critical distrust displayed by some investgators is weighed agarnst the over-enthusiasm of others. Each new contribution to the literature must therefore be accepted only tentatively and the conclusions drawn by the various clinicians must be carefully balanced one against another.

This paper presents a series of 203 cases of anaesthesia with 2 brom, 2 chlor, I,I,I, fluor,-ethane, which has become known as Fluothane and which will be referred to as such throughout this paper. Thus mvestigation has been carried out over the period from October 31, 1956, to May 1, 1957, and includes a full range of surgical procedures as well as obstetrical deliveries performed under this new anaesthetic agent, as shown in Table I

TABLE I

\begin{tabular}{|c|c|c|c|}
\hline $\begin{array}{l}\text { Type of procedure or } \\
\text { region involved }\end{array}$ & Number & $\begin{array}{l}\text { Type of procedure or } \\
\text { region molved }\end{array}$ & Number \\
\hline Obstetrical vaginal delivery & 18 & ENT & \\
\hline Inguninal & 5 & Mouth, throat, dental & 12 \\
\hline Intrathorąic & & Ear & 5 \\
\hline Pulmonary and cardrovascular & 10 & Nose and sinuses & 8 \\
\hline Thoraco-abdominal & 1 & Neck major and minor & 9 \\
\hline Upper abdominal & & Peripheral nerves & 3 \\
\hline Májor & 15 & Perineal & \\
\hline Minor & 1 & Genito-urinary & 10 \\
\hline Peripheral vascular arterial & 4 & Gastro-intestinal & 4 \\
\hline Chest-wall minor & 2 & Gynaecological & 14 \\
\hline $\begin{array}{l}\text { Spinal column } \\
\text { Laminectomy }\end{array}$ & 5 & $\begin{array}{l}\text { Intracranial } \\
\text { With hypothermia }\end{array}$ & 4 \\
\hline $\begin{array}{l}\text { Laminectomy } \\
\text { Cervical or lumbo-sacral fusion }\end{array}$ & 6 & Without hypothermia & 3 \\
\hline Lower abdominal & & Extremities & \\
\hline Genito-urinary & 4 & Hip (S P Nailing or Moore & \\
\hline $\begin{array}{l}\text { Gastro-intestinal } \\
\text { Gynaceological }\end{array}$ & $\begin{array}{l}5 \\
6\end{array}$ & $\begin{array}{l}\text { Arthroplasty) } \\
\text { Other mayor orthopaedic }\end{array}$ & $\begin{aligned} \pm \\
12\end{aligned}$ \\
\hline Eyes & 13 & Plastic and minor procedures & 20 \\
\hline
\end{tabular}

\section{Methods of Investigation AND Apparatus}

In order to eliminate one of the most important sources of experimental errorthat arising from deffering interpretations of observed facts $\rightarrow$ all cases included in this series are those in which anaesthesia was personally administered by the author.

In this series, Fluothane was administered by several inhalational methods. In all except the open drop cases, oxygen has comprised 50 per cent or more of

-Department of Anaesthesia, University of Toronto and Toronto General Hospital. 
the vehicular gas mixture, the only other component of which has been nitrous oxide. Table II shows the type of curcut or the method used and the number of patients for which each was used.

TABLE II

\begin{tabular}{lr}
\hline Method & Number \\
\hline Open drop on gauze mask & 2 \\
Closed, $\mathrm{CO}_{2}$ absorption & 10 \\
Semi-closed, circle CO absorption & 23 \\
Semi-closed, to-and-fro $\mathrm{CO}_{2}$ absorption & 9 \\
Continuous flow (semi-open) non-rebreathing gas flow of 8 to 12 litres & 159 \\
$\quad$ per minute & \\
\hline
\end{tabular}

Very limited experience of the open drop method shows it to be practical and. possibly of value for mass casualty anaesthesia The closed method with $\mathrm{CO}_{2}$ absorption is not considered desirable, as one has no idea of the concentration of the drug in the curcuit, and wide fluctuations of blood pressure and pulse occur. The semi-closed method with $\mathrm{CO}_{2}$ absorption (circle or to-and-fro) allows greater control of the drug, and therefore provides much smoother anaesthesia; the higher the gas flow, the greater the ease of maintaining reasonable levels of blood pressure, pulse and respiration, but variations occur more frequently than is desirable.

In the author's opinion the contunuous flow semi-open or non-rebreathing technique using gas flows of eight to twelve htres is the technique of choice for the administration of Fluothane It allows maximal control of concentration and the greatest ease of control of blood pressure level, pulse and respiratory rate.

Since Fluothane is a volatile liquid it must be vaporized for use in anaesthesia. A number of vaporizing chambers have been investigated or devised. The types used in this series and the number of cases done with each are shown in Table III

TABLE III

\begin{tabular}{lc}
\hline Type of vaporizing chamber & Number of cases \\
\hline Ether vaporizer (Heidbrink) & 1 \\
(a) wick removed & 27 \\
(b) wick above fluid level & 1 \\
(c) wick below fluid level & 8 \\
Row Jotham replaced with tube above fluid level & 12 \\
Trlene Vaporizer (B O C Boyle's Type) with no special calıbration & 8 \\
Fluotec (Cyprane) Vaporizer & 144 \\
\hline
\end{tabular}

Since most of the gas machines in use at the Toronto General Hospital are Heidbrink Machines of one type or other, the ether vaporizer of this equpment was the most readily avalable chamber for Fluothane. With the wick removed almost no Fluothane comes through the circuit. With the wick in place and approximately $40 \mathrm{ml}$ of Fluothane in the bottle a fair degree of control is 
possible, but is not constant, owing to changes in fluid level and temperature. With the fluid level above the bottom of the wick, alarmingly. high concentrations of Fluothane are obtained which are relatively uncontrollable. Replacing the wick with a tube extending down to a point near the fluid level provides control much like that obtained with the wick above the fluid level.

The Rowbotham Bottle with a non-rebreathing high flow method provides good control with adequate and apparently safe concentrations of Fluothane. The bottle must be refilled frequently.

The British Oxygen Company Boyle's T.C.E. vaporizer provides reasonable safety and control. However, because of changes in temperature and fluid level, the concentrations obtained vary greatly and the vaporizer requires constant adjustment.

The "Fluotec" (Cyprane) Vaporizer is a controlled percentage vaporizer manufactured in England. With the non-rebreathing technique it provides a most satisfactory and safe method for the administration of Fluothane. The degree of control achieved with this temperature compensated vaporizer is analagous to that provided by the flowmeter for cyclopropane and other gases. The "Fluotec" has been

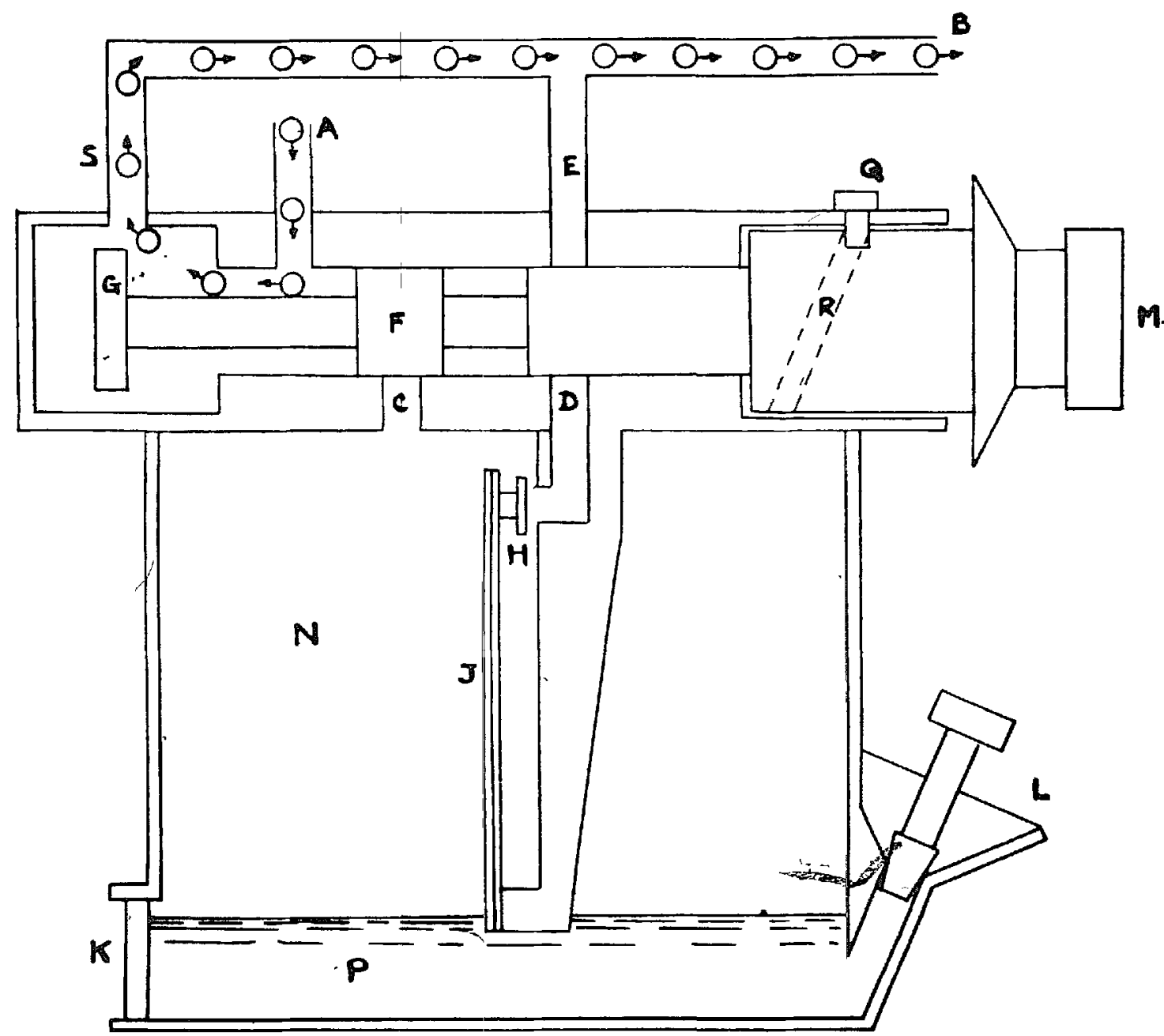

Figure 1. The "Fluotec" Vaporizer in the "off" position. 


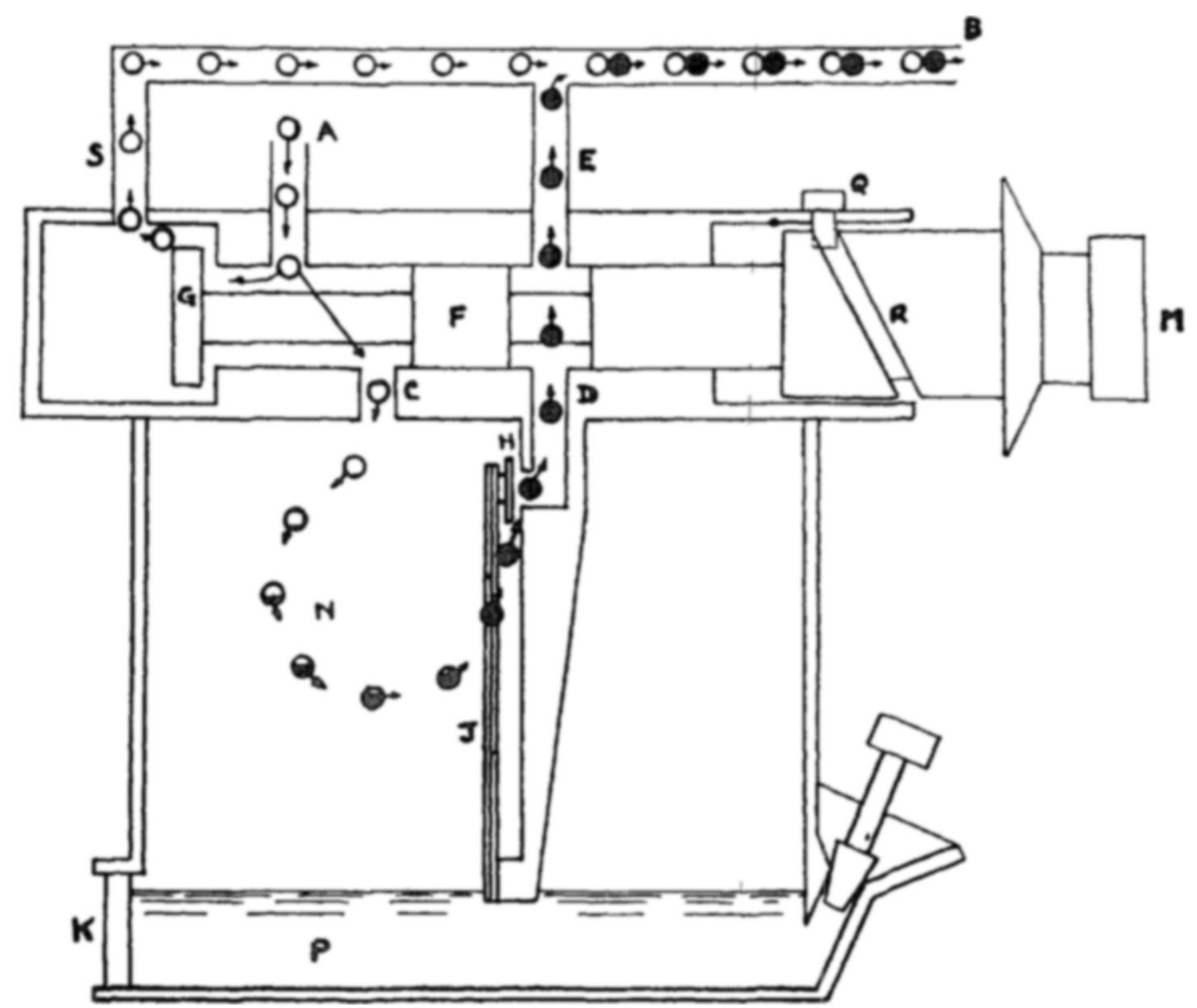

FIGune 2. The "Fluotec" Vaporizer in the open or any calibrated position.

used with both semi-closed and non-rebreathing methods of gas administration and, although originally designed for only continuous flow circuits, has proved equally useful for carbon dioxide absorption methods in which a high flow of gases (four litres per minute or greater) is used. With a non-rebreathing technique and an adequate gas flow the inspired concentration of Fluothane can be controlled very accurately. If a partial rebreathing technique is used the degree of accuracy is, of course, not so high, but control may be exercised in this method and in the semi-closed carbon dioxide absorption circuit just as one controls the anaesthetic gases.

The "Fluotec" is individually calibrated to deliver 0.5 per cent to 3.0 per cent Fluothane vapour by volume, within a gas Hlow range from 4 to 16 litres per minute. The calibrations are at $1 / 10$ per cent intervals. The vaporizer has an automatic temperature compensated valve, so that the percentages being delivered are accurate over a temperature range from $55^{\circ}$ to $90^{\circ} \mathrm{F}$. The designer's claim of maximal variation of 20 per cent in Fluothane concentration at any calibration setting has been confirmed by tests carried out in the Department of Pharmacology at the University of Toronto.

Although this vaporizer is designed primarily to fit a Boyle's machine (B.O.C. 
or M.I.E.) it can be readily adapted to any other make of machine. It is a heavy, accurately machined, completely closed and sealed piece o: apparatus, with a clear glass level window, leak-proof filling funnel and drain $\mathrm{pl} \mathrm{lg}$ (Fig. 3). Figures 1 and 2 will provide some idea of the mechanism of the "Fluotec." Figure 1 shows it in the "off" position. Figure 2 shows it in the open, or calibrated, position. Referring to Figure 1 (off), metered gas enters at A and as shown by the arrow it meets the spindle $F$, goes through the by-pass valve $G$, along the port $S$ to $B$ and thence to the patient None of the gas can enter or leave the vaporizing chamber $N$ as ports $C$ and $D$ are closed by spindle $F$. Rotation of the control $M$ causes the spindle $F$ to move to the right by virtue of the spiral groove $\mathrm{R}$.

As the spindle $F$ moves to the right the ports $C$ and $D$ are opened and the opening of the by-pass port $G$ is considerably reduced. This results in the "open" position. In the "open" position (Fig. 2) metered gas enters at A and on reaching the spindle $F$ divides, some going through the by-pass $G$ as in the "off" position, and some going through port $\mathrm{C}$ into the vaporizing chamber $\mathrm{N}$. Here the gas picks up "Fluothane" vapour and passes on through the valve $\mathrm{H}$. Valve $\mathbf{H}$ is thermostatically adjusted by means of the bi-metallic strip $\mathrm{J}$, so that the valve controls the outtlow of the Fluothane-laden gas according to the temperature in the vaporizer. This rich gas, having passed the valve $\mathbf{H}$, goes along to port $D$ to $E$ at the end of which it joins and mixes with the "clean" gas from S. The filling funnel is illustrated at $\mathrm{L}$, and $\mathrm{K}$ is the level window.

Preoperative medication has been deliberately uncontrolled in this series, and all types were used as is shown in Table IV. Most of these patients were given a moderate bedtime dose of barbiturate (usually Seconal gr. $\overline{1 s s}$ ) the night before operation.

TABLE IV

\begin{tabular}{lc}
\hline Preoperative medication drug or combination of drugs & Number of cases \\
\hline Ojiate with atropine & 21 \\
Ojiate with scopolamine & 84 \\
Demerol with atropine & 38 \\
Demerol with scopolamine & 36 \\
Demerol with Phenergan & 8 \\
Atropine alone & 1 \\
Opiate alone & 1 \\
Opiate with barbiturate & 1 \\
Largactil with Dernerol & 1 \\
Largactil, Demerol, Phenergan & 5 \\
\hline
\end{tabular}

\section{INDUCTION OF ANAESTHESIA}

In 174 patients induction of anaesthesia was performed by the intravenous injection of a thiobarbiturate in $2 \frac{11}{2}$ per cent solution the common drug used was thopentone although thioamylal was used in a few cases. The dose for induction varies from $100 \mathrm{mgm}$. to $450 \mathrm{mgm}$ with an average dose range of $150-250 \mathrm{mgm}$. For the remaining 29 patients either barbiturates or the intravenous approach were contraindicated. 27 were induced by Fluothane vapour in a mixture of 


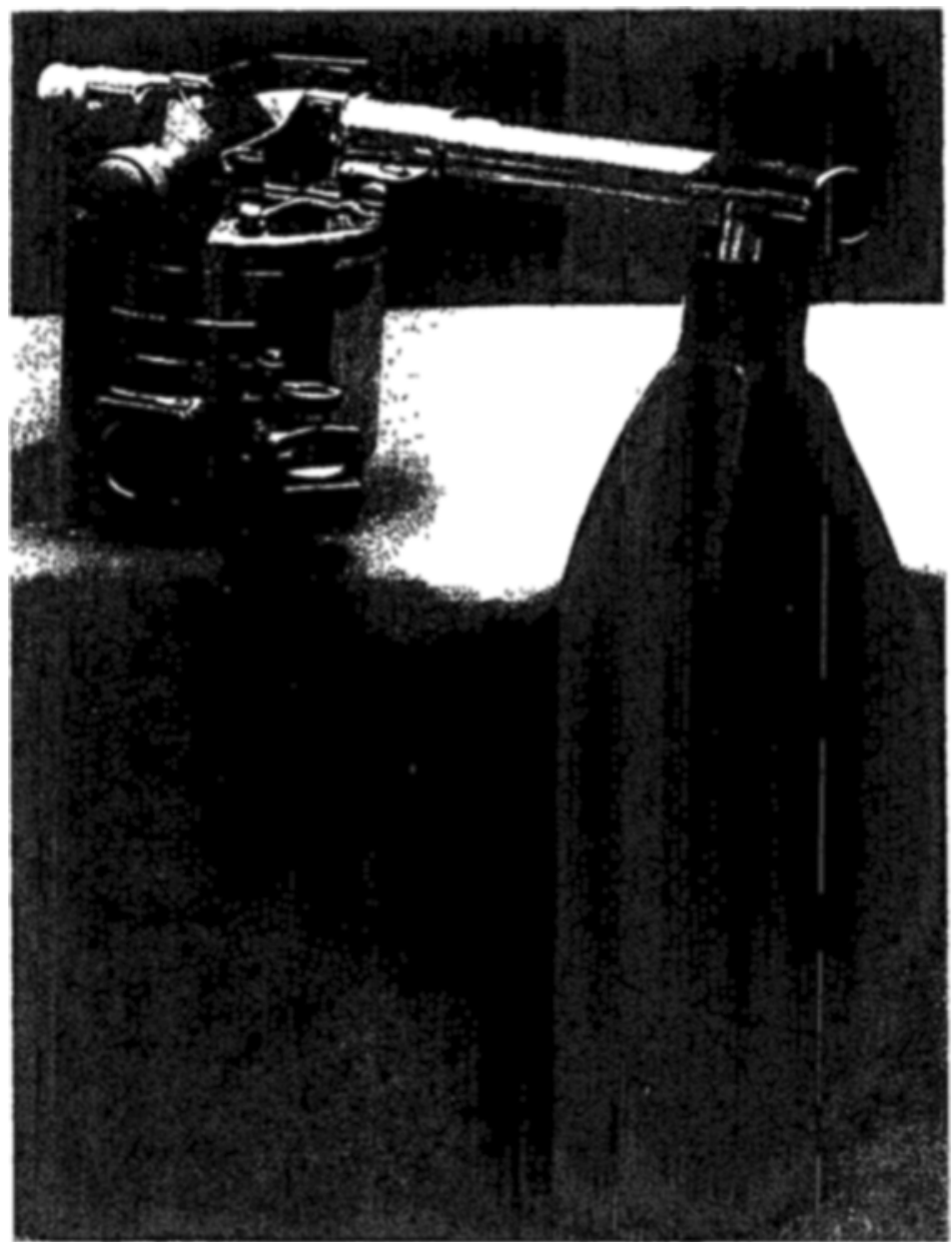

FIgure 3 The "Fluoter" Calibrated Vaporizer for Fluothane 
nitrous oxide and oxygen in the 50/50 ratio; the remaining 2 by the open drop method.

Intubation, when performed, has usually been facilitated by the intravenous injection of 10-100 mgm, of succinylcholine chloride. For most patients the larynx has been sprayed before intubation with a topical anaesthetic agent. Occasionally neither spray nor relaxant has been used.

Ventlation with nitrous oxide and oxygen $50 / 50$ has been carried out for all patients following intubation until spontaneous respirations have been re-established, before Fluothane has been introduced into the crrcuit.

\section{Maintenance of ANaestimesia}

Anaesthesia has been mantained with Fluothane in a vehicle of oxygen or a 50/50 mixture of nitrous oxide with oxyger:

Relaxant drugs have been used for 37 patients, after Fluothane was started or for purposes other than the facilitation of intubation. For 19 succinylcholine chloride has been used by continuous drip technique. For 6 it has been given intermittently. Gallamine has been given intermittently throughout operation to 10 patients. Only 2 received d-tubo-curarine as a relaxant. For both the dose used was small and no adverse effect was seen. Demerol has been given to 12 patients by intermittent intravenous injection as an adjunct to anaesthesia. No incompatible reaction has been observed. Largactil (chlorpromazine) has been used for two patients with hypothermia to control shivering in the rewarming period. In both sharp falls in blood pressure occurred at once and the procedure has now been abandoned.

\section{Special Procedures}

Continuous visual E.C.G. control has been available for 9 patients only. In 7 cases the Monaghan Respirometer (Bennett) has been used to observe the degree of respiratory depression accompanyng muscle relaxation due to Fluothane. Arrangements have been completed for Fluothane estımations in blood samples and in spot gas samples This work has been begun and will be reported at a later date.

\section{Clinical Observations}

This colourless, volatile liquid has a relatively pleasant odour which is somewhat confusing to most anaesthetssts because of its marked.similarity to that of both trichlorethylene and chloroform. The vapour appease to be non-irritating and even in concentrations up to 2.5 per cent is well tolerated by the conscious as well as the unconscious patient. I have seen no evidence of dermattis caused. by contact with the vapour in the concentrations used clinically.

Although laboratory experiment has shown that liquid Fluothane attacks rubber, plastics, stainless steel, aluminium and tin, I have seen no evidence as yet of deterioration of any of the equipment used for the administration of Fluothane anaesthesia. However, it is worthy of note that the "Fluotec" Controlled Percentage Vaporizer must not be inverted or tipped from the upright position as 
the sealing cement and gaskets are quickly attacked by any liquid in the chamber. This happened to the first vaporizer used in this series. The manufacturers recommend draining of the Fluothane chamber when the "Fluotec" is not in use.

The type of preoperative medication seems to have had little effect on either induction or maintenance of anaesthesia in this serjes. The incidence of hypotension during anaesthesia and of vomitung both during and after anaesthesia bears no significant relatıonship to type of preoperatıve sedation.

Induction of anaesthesia has been performed easily and smoothly in most cases. The short stage of excitement which was noted with the open drop method and on induction with Fluothane, nitrous oxide and oxygen was not in evidence after induction with an intravenous barbiturate. The highest concentration necessary for induction of anaesthesia was 30 per cent for one neurosurgical hypothermia procedure. For other hypothermia cases 2.5 per cent was necessary With children the highest concentration necessary was 20 per cent. When a barbiturate was used for induction the highest concentration of Fluothane required was usually 2.0 per cent. Occasionally 2.5 per cent was used for two or three minutes.

In all patients not requirng deep relaxation, anaesthesia was readily maintained with a concentration of 10 per cent or less. For many only 0.5 per cent of Fluothane was necessary. Except in those cases in which the relationship between relaxation of muscles and depth of respiration was being investigated, the relaxation necessary for surgery was obtained with the use of various intravenous relaxing agents. Succinylcholine drip, intermittent succmylcholine and gallamine seemed to be equally satisfactory. Curare given to two patients in small doses (less than $15 \mathrm{mgm}$. total) did not produce any ill effect, but the method was not continued in this series. In all patients for whom relaxant drugs were used respirations were assisted or controlled.

Extreme variation in blood pressure was the most strikng and troublesome complication of Fluothane anaesthesia. Hypotension occurred in 56 patients. This is defined as a drop in systolic pressure to a level of $80 \mathrm{~mm}$. of mercury or lower, or a drop of $60 \mathrm{~mm}$. of mercury in a normally hypertensive patient. Statistically this tendency cannot be related to the type of preoperative medication, although it appeared to be slightly less frequent when Demerol and atropine had been used. In 44 of these patients the chief pressure drop occurred immediately after induction. In 12 the hypotension occurred later in the operation or the blood pressure fell gradually throughout the period of anaesthesia. In a few cases the blood pressure picture has been quite bizarre with high and low spiking-within normal limits however. The systolic blood pressure of 8 patients rose etther slowly or sharply and remained elevated.

The initial fall in blood pressure is of great interest. In a minor degree it occurred in almost all patients induced with an intravenous barbiturate and it was rare in those induced with Fluothane. It would appear that the fall in blood pressure may be due to the barbiturate and that the Fluothane may merely have prevented the usual rapid recovery.

A fall in blood pressure was much less common in those patients for whom the non-rebreathing system and the "Fluotec" vaporizer were used than with any other apparatus or method One patient however, anaesthetzed with the "Fluotec" 
for suıgery under hypothermia, had been taking reserpine for some months until two days preoperatively. This patient's blood pressure was most difficult 'o control.

Blood pressure fall was most frequent with the closed $\mathrm{CO}_{2}$ absorption system and in those patients in whom good relaxation was acheved with Fluothane alone.

Hypotension was effectively corrected in most patients with methedrine $10-20$ mgm. given intravenously. In only one neurosurgical case was it necessary-after the patient had received Largactil-to give norepinephrine by intravenous drip.

The pulse rate appeared in this senes to be far from consistent. Although when a profound blood pressure fall occurred the pulse -ate seemed to parallel it more or less closely; yet a rapid rise in pulse rate, ap jarently unconnected with carbon dioxide retention, was quite common.

The respiratory rate, although occasionally depressed to 16 per minute, showed a general tendency to rise to a level of about 30 per minute and frequently higher. The depth of res jration became much less as the rate was elevated. Measurements with the Monaghan Respirometer indicated that when fair abdominal relaxation was achieved the tidal volume was reduced to a very low figure, and that although the rate rose to 60 per minute the minute volume was only 6 litres.

One very interesting observation was made during intrathoracic procedures. With Fluothane anaesthesia control of respirations may very often be achieved and maintained merely by replacing the patient's spontaneous effort. Using a concentration of Fluothane of 0.7 per cent or less and without the use of relaxing agents, a quiet field may be provided for the surgeon. Most of these patients were given minumal unit doses (10-20 mgm.) of Demerol to aid the effect but the Demerol could probably have been dispensed with.

In spite of theoretical objections adrenaline has been given in a local anasthetic drug by infiltration to several patients under Fluothane. There has been no adverse effect. Atropine given during Fluothane anaesthesia raises a depressed blood pressure if the pulse rate has also been depressed.

Cardiac irregularities have been observed in six patients. Three cases were cardiac surgical procedures. One was a neurosurgical hypothermia in which a tight brain was probably responsible. In this case apnoea also occurred at the same time The introduction of a brain needle corrected both phenomena but the operation was terminated and on rewarming the patient appeared quite normal.

Vomiting has occurred infrequently in this series. Four patients vomited during anaesthesia, three of them regurgitating around a duodenal tube when the surgeon squeezed the stomach. Six patients vomited once during the immediate postoperative period One other patient is known to have vomited during the twelve hours following anaesthesia, and others may have done so without our knowledge A small number of patients complaned of mild nausea on waking but did not vomit.

Salivary secretions have been troublesome in only four patients at the end of operation

One of the most striking observations has been the short waking period following Fluothane anaesthesia, and the rapid return of mental orientation. This has often been immediate and all patients of the series seem to have been alert within 30 minutes of the end of the procedure. 
Postoperative analgesia has been poor and the patients require sedation very soon.

In the eighteen vaginal deliveries performed under Fluothane it was noted that nine patients showed evidence of uterine relaxation to a troublesome degree. Decrease in Fluothane concentration seemed to correct this. There was no observable effect on the baby in any of these cases.

One death has occurred in this series. One neurosurgical patient operated on under Fluothane and hypothermia bled twelve hours postoperatively, possibly owing to Largactil given in the warming perıod, and died four days postoperatively.

\section{CONCLUSTONS}

Fluothane is a very potent anaesthetic agent and should be administered with care, as minor variations in concentration may produce profound effects. It is probably inadvisable to give Fluothane by the closed $\mathrm{CO}_{2}$ absorption technique and the most satisfactory and the safest method at present available appears to be the non-rebreathing contmuous flow circuit (nitrous oxide and oxygen) with the "Fluotec" temperature compensated vaporizer.

Type of preoperative medication has little, if any, influence on the course of Fluothane anaesthesia.

Succinylcholine and gallamine may be quite safely used with Fluothane.

Abdominal relaxation cannot be achieved with Fluothane alone without producing a marked respiratory depression.

A fair degree of respiratory control for intrathoracic surgery can be achieved with Fluothane.

The most favourable characteristics of Fluothane appear to be potency, acceptability to the patient, a rapid waking period and relative freedom from postoperative side effects.

\section{ACKNOWLEDGMENTS}

The author is indebted to Ayerst, McKenna and Harrison Co of Canada for the generous supplies of Fluothane made avalable for this investigation, to $\mathrm{Mr}$. Fraser Sweatman for the loan of a "Fluotec" Calibrated Vaporizer and to Dr. Werner Kalow of the Department of Pharmacology, University of Toronto, for checking the vaporizer's calıbrations and for his continuing co-operation

\section{SUMMARY}

A series of 203 surgical and obstetrical patients anaesthetized with Fluothane at the Toronto General Hospital is presented. The methods and technique used and special apparatus available are discussed and clinical observations are given in detail.

\section{RÉSUMÉ}

Dans le but d'apprécier les effets du nouvel anesthésique liquide volatil Fluothane, nous avons fait, à l'hôpital Toronto General, des épreuves cliniques. 
Nous présentons deux cents cas. Tous les patients ont été anésthésiés par l'nnvestigateu lu1-même.

Les méthodes d'administration employées ont été le goutte à goutte; le sem fermé avec absorption du gaz carbonıque, le crrcuit fermé avec absorption $d_{1}$ gaz carbonique et le flot contınu sans rémspiration. Nous avons aussi employś les techniques de pression positive et négative dans quelques cas de thorax ouvert.

Cette substance a été évaporée dans des appareıls variés dont la boutelle à éther Heidbrınk, la bouteille Rowbotham, la boutelle "Trilène" des machines Boyle et Marrett. L'apparesl le plus utıle a été le vapornsateur à pourcentage contrôlé Cyprane (Fluotec). Nous avons employé ce vaporısateur, possédant une grande précision et un système compensateur pour la température et la vitesse du courant gazeux, 'aussı bien en semi-fermé qu'en Alot continu et, cela, avec d'excellents résultats. Avec ce vaporssateur, le flot continu constitue la méthode de choix pour l'administration du Fluothane

Nous avons, dans notre série de cas, tous les types de chirurgie majeure et mineure. Nous avons employé l'appareil Cyprane pour 145 de ces cas.

Nos observations nous permettent de dire que ce médicament peut être à la fois utıle et dangereux Les avantages les plus transcendants du Fluothane sont: qu'il n'est pas inflammable $\mathrm{nu}$ explosif et il permet une induction agréable et un réveil rapıde. La farble incidence des vomissements post-opératoires est surprenante.

Ses pires inconvénients sont: une tendance à produire de l'hypotension et à avoir des effets imprévisıbles sur les systèmes respiratorre et cardiovasculaire. L'effet hypotenseur est dıfficile à exploiter car il s'accompagne d'un suintement sanguin marqué dans le champ opératoire.

Selon toute apparence, l'évaporation du médicament sur l'appareillage est sans conséquence

Ce médicament constitute une addition à notre armamentarium. Il ne remplacera pas l'éther mais il pourra jouer un rôle important. 